\title{
Schottky diyot tabanlı UV detektörlerde seri direnç etkileri
}

\author{
Şadan ÖZDEN* \\ Muğla Sitkı Koçman Üniversitesi, Fen Fakültesi, Fizik. Bölümü, Kötekli, Muğla \\ Geliş Tarihi (Received Date): 12.08.2018 \\ Kabul Tarihi (Accepted Date): 22.03.2019
}

\section{Özet}

Bu çalışmada GaN tabanlı UV algllayıcı GUVA S12SD Schottky diyotun sicaklık bağımlı akım - voltaj karakteristikleri seri direnç etkileri yönünden incelenmiştir. Bu amaçla FPGA tabanll, basit ve düşük maliyetli bir ölçüm sistemi hazırlanarak, başarıyla kullanılmıştır. Sonuçlar, aygıtın akım iletim mekanizmasının termiyonik yayılımla açıklanabileceğini göstermektedir. Seri direnç hesapları için iki farklı yöntem kullanılmış ve birbiri ile büyük uyuma sahip sonuçlar elde edilmiştir. İdealite faktörü ve seri direncin sıcaklık bă̆ımlılı̆̆ından, ara yüzeydeki durumların ve buradaki yük taşlyıcılarının aygıt karakteristikleri üzerinde etkin olduğu belirlenmiştir.

Anahtar kelimeler: UV, Schottky diyot, GaN, seri direnç, FPGA.

\section{Serial resistance effects on Schotky diode based UV dedectors}

\begin{abstract}
In this study, the temperature dependent current - voltage characteristics of GaN based UV sensor GUVA S12SD Schottky diode were investigated in terms of series resistance effects. For this purpose, a FPGA based simple and low cost measurement system has been prepared and employed successfully. The results show that the current transport mechanism of the device can be explained by means of thermionic emission. Two different methods were used for the series resistance calculations and their results were consistent with each other. According to the temperature dependent ideality factor and series resistance, it has been determined that interface states and charge carriers on the states effect on device characteristics.
\end{abstract}

Keywords: UV, Schottky diode, GaN, serial resistance, FPGA.

\footnotetext{
*Şadan ÖZDEN, sozden@mu.edu.tr, https://orcid.org/0000-0003-0716-9194
} 


\section{Giriş}

Gelişen sanayileşmenin sonucunda, değisşen atmosferik koşullara bağlı olarak yeryüzüne ulaşan güneş ışınlarında da bir artış söz konusudur. Bu artış küresel ısınmanın yanı sıra mor ötesi (UV) 1şığın etkilerinde de değişiklikleri beraberinde getirmektedir. İnsan sağlığı üzerindeki olumsuz etkilerinden kaçınmak amacıyla bu ışınların UV endeksinin doğru belirlenmesi de bu nedenle daha çok önem kazanmaktadır. Ayrıca UV ışınlar; kimyadan, sterilizasyona, tıptan, test - ölçüm sitemlerine kadar geniş bir uygulama alanına sahiptir. Dolayısıyla UV ışınların belirlenmesi ve ölçülmesi günümüzde popüler araştırma alanlarından biridir [1]. Bu amaçla geliştirilen GaN ve AlGaN tabanlı aygitlar sirasıyla spektrumun görünür ve güneş 1şığı bölgelerine gösterdikleri körlük nedeniyle maliyeti arttırıcı UV filtrelere ihtiyaç duymazlar. Diğer yandan basit yapıları ve düşük maliyetli üretime olanak sağlamaları nedeniyle de UV kaynak veya algılayıcı üretimi için öne çıkmaktadırlar. UV algılayıcı sistemler arasında GaN tabanlı Schottky eklem aygıtlar son yıllarda yaygın bir şekilde üretilmeye ve kullanılmaya başlanmıştır [2]. Her $\mathrm{p}-\mathrm{n}$ veya Schottky tabanlı eklem aygıt içersinde, akım iletimini etkileyen parametrelerin doğru belirlenmesi uygulama açısından önemlidir. Bu çalışmada UV alg1layıc1 $\mathrm{GaN} / \mathrm{Al}_{2} \mathrm{O}_{3}$ tabanl1 Schottky eklem aygitı olan GUVA S12SD'nin akım voltaj karakteristiklerine yüksek sıcaklık bölgesindeki seri direnç etkisi incelenmiştir. Ölçümler için de alternatif ve düşük maliyetli bir sistem önerilmiştir.

\section{Deneysel}

Bu çalışmada kullanılan GUVA S12SD UV algılayıcısı yüzey montaj (SMD) yapıda GaN tabanlı bir Schottky diyottur ve ticari olarak temin edilmiştir. Aygit, GaN/ $/ \mathrm{Al}_{2} \mathrm{O}_{3}$ eklemi içermektedir. Üst kontak altın $(\mathrm{Au})$ ve alt kontak gümüş pasta $(\mathrm{Ag})$ ile sağlanmıştır [3]. Yine üzerinde pencere olarak Si koruyucu tabaka bulunmaktadır.

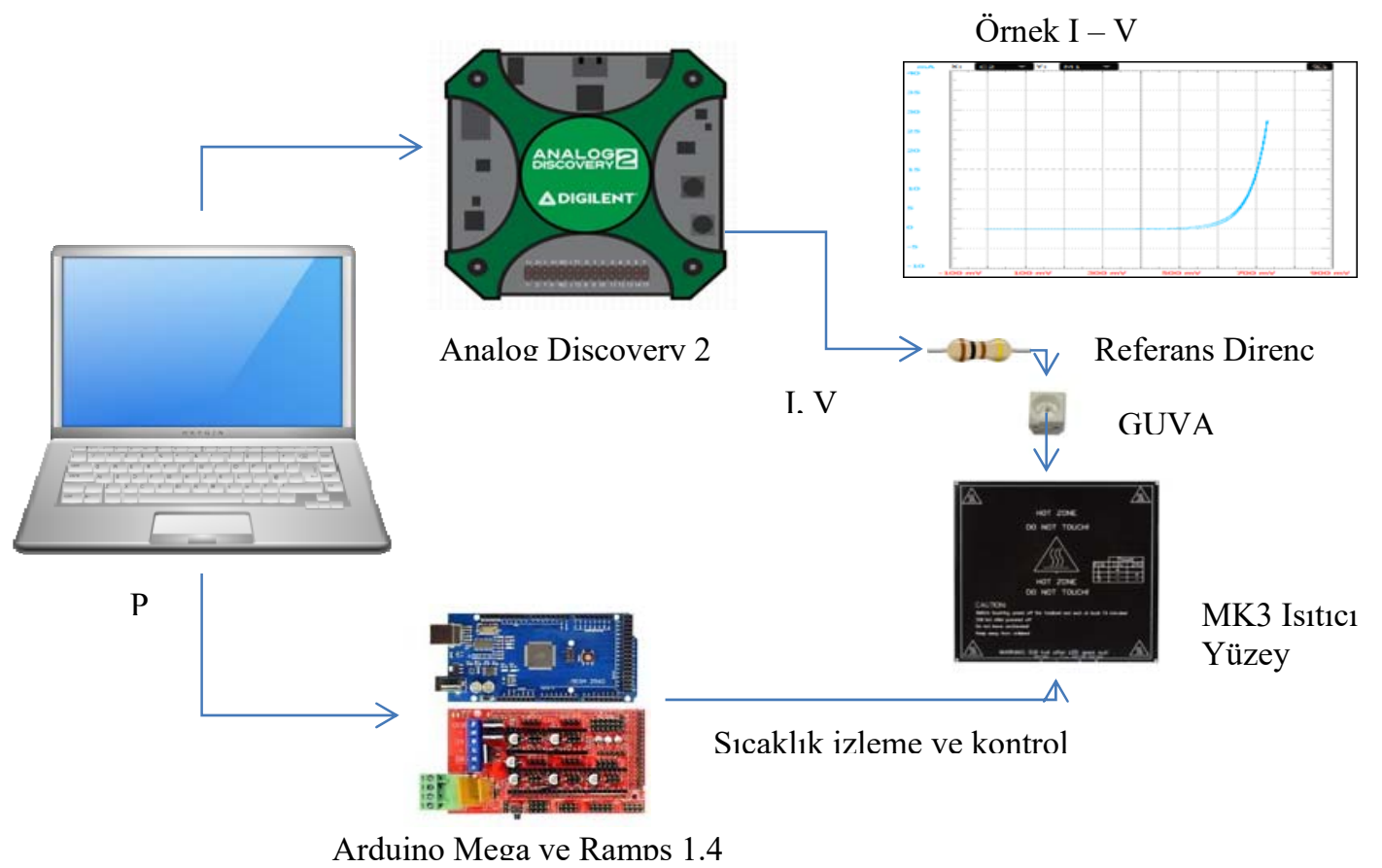

Şekil 1. Çalışmada kullanılan ölçüm sistemi ve örnek I - V grafiği. 
Aygıtın elektriksel karakterizasyonu için geleneksel cihazlardan farklı olarak basit ve düşük maliyetli iki sistem kullanılmıştır. Bunlardan ilki akım - voltaj karakteristiklerini elde etmek için kullanılan eğri izleme (curve tracer) sistemidir. Bu amaçla iki kanallı osiloskop ve sinyal jeneratörünü tek bir FPGA tabanlı devre içinde sunan Analog Discovery 2 cihazı kullanılmıştır. Ölçümü yapılan aygıt üzerine referans bir direnç üzerinden uygulanan $400 \mathrm{~Hz} 5 \mathrm{~V}_{\mathrm{p}-\mathrm{p}}$ üçgen dalga formundaki sinyal için cihazın programı aracılığ ile akım ve voltaj ölçümleri gerçekleştirilerek direkt I-V karakteristiği elde edilmiştir [4] Sıcaklık kontrolü ve ölçümü için ise 3D yazıcılarda kullanılan 1sitıcı yüzeyden yararlanılmıştır. $10 \mathrm{~cm}$ x $10 \mathrm{~cm}$ alana sahip 1 sitıcı rezistans kaplı bu yüzeye yerleştirilen örneğin sıcaklığı, 100k $\Omega$ NTC (sıcaklıkla direnci azalan termistör) algılayıcılarla ölçülmüş ve bilgisayara bağlı Arduino Mega + Ramps 1.4 kartlarıyla da kontrol edilmiştir. Bu sistem aracılığ 1 ile $0,1 \mathrm{C}$ hassasiyetle sicaklık ölçüm ve kontrolü yapılabilmektedir. Tüm ölçüm sisteminin blok şeması ve programdan alınan örnek I - V grafiği Şekil 1'de verilmiştir.

\section{Araştırma bulguları}

GUVA S12SD UV Schottky diyot için karanlıkta, 23 - $103{ }^{\circ} \mathrm{C}$ sıcaklık aralığında ölçülen akım - voltaj karakteristikleri Şekil 2'de verilmiştir. Düşük voltajlarda benzer karakteristiğe sahip olan akım eğrilerinin $0,7 \mathrm{~V}$ üzerindeki ileri besleme voltajlarında, seri direnç etkisine bağlı olarak sınırlandığı ve sıcaklığa kuvvetle bağlı hale geldiği görülmektedir.

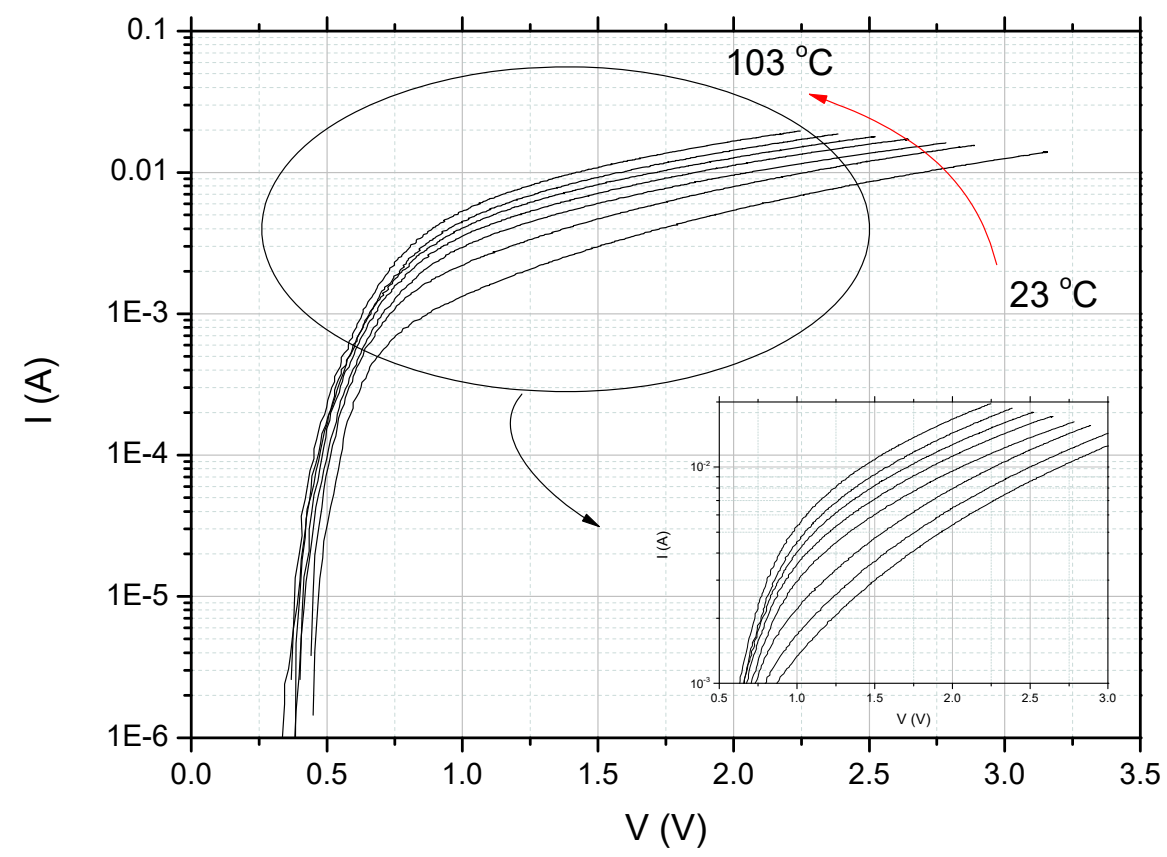

Şekil 2. GUVA S12SD Schottky diyot için karanlıkta ölçülmüş sıcaklık bağımlı I - V karakteristikleri.

Metal - yariiletken (MS) ve metal - oksit - yariletken (MOS) aygıtlar için ileri besleme altındaki akım iletimini açıklayan termiyonik yayılım mekanizması, seri direnç etkisi de göz önüne alınarak, 
$\mathrm{I}=\mathrm{I}_{0}\left[\exp \left(\frac{\mathrm{q}\left(\mathrm{V}-\mathrm{IR}_{\mathrm{S}}\right)}{\mathrm{nkT}}\right)-1\right]$

şeklinde ifade edilebilir. Burada $I_{0}$ ters besleme doyma akımı, $k$ Boltzman sabiti, $T$ mutlak sıcaklık, $R_{S}$ seri direnç etkileri ve $n$ diyot için ideal davranıştan ne kadar uzak olduğunu gösteren idealite faktörüdür [5-8], Bu ifade göz önüne alınarak yüksek voltajlardaki seri direnç etkilerinin belirlenmesi için Norde'den başlayarak farklı yöntemler geliştirilmiş ve kullanılmıştır [9-10]. Bu yöntemlerin en yaygın kullanılanlarından biri Cheung yöntemidir [11] ve

$\frac{\mathrm{dV}}{\mathrm{d}(\ln \mathrm{I})}=\mathrm{IR}_{\mathrm{s}}+\mathrm{n}\left(\frac{\mathrm{kT}}{\mathrm{q}}\right)$

ifadesi kullanılarak seri direnç ifadesi elde edilebilir. Buradan görüleceği üzere akımın doğal logaritmasının voltaja karşı türevi alınır ve akıma karşı çizilirse elde edilen değişim doğrusal olacak ve eğimi direkt $R_{S}$ değerini verecektir. Yine bu doğrunun $d V /(d(\ln I))$ eksenini kestiği noktadan yüksek voltajlardaki $n$ değerleri hesaplanabilir. Farklı sıcaklıklarda (2) ifadesini kullanılarak hesaplanan seri direnç değerleri Tablo 1'de verilmiştir. Yine Şekil 3'de sıcaklığa bağlı olarak $n$ faktörünün nasıl değiştiği gösterilmiştir.

Tablo 1. GUVA S12S Schottky diyot için farklı sıcaklıklarda Cheung yöntemine göre hesaplanan seri direnç $\mathrm{R}_{\mathrm{s}}$ değerleri.

\begin{tabular}{|c|c|c|c|c|c|c|c|c|}
\hline $\begin{array}{c}\text { Sicaklık } \\
\left({ }^{\circ} \mathbf{C}\right)\end{array}$ & 23 & 33 & 43 & 63 & 73 & 83 & 93 & 103 \\
\hline $\boldsymbol{R}_{\boldsymbol{s}}(\boldsymbol{\Omega})$ & 72,5 & 74,18 & 93,22 & 111,05 & 104,49 & 97,00 & 94,26 & 86,60 \\
\hline
\end{tabular}

$\mathrm{Bu}$ değişim incelendiğinde artan sıcaklıkla birlikte $\mathrm{n}$ faktörünün azaldığ 1 görülmektedir. Ayrıca idealite faktörü n'in 1'den çok büyük değerler aldığ 1 da izlenmektedir. $\mathrm{Bu}$ durum termiyonik yayılım mekanizmasından sapmalara işaret etmektedir. Bu sapmanın nedeninin belirlenmesi için sıcaklık bağımlılığına daha yakından bakıldığında $n$ idealite faktörünün

$\mathrm{n}(\mathrm{T})=\mathrm{n}_{0}+\frac{\mathrm{T}_{0}}{\mathrm{~T}}$

şeklinde verilebildiği belirlenmiştir. $n_{0}$ ve $T_{0}$ sabitler olmak üzere bu ifade Şekil 3 'de görülebileceği gibi deneysel verilere tam fit etmektedir. Bu durum da aygit üzerinden geçen akım ifadesini termiyonik alan yayılım mekanizmasıyla ifade edilebileceğini ve etkin yüzey durumları ile metal yarıiletken arasındaki yalıtkan tabakanın konumsal dağılımının aygıt üzerinde etkin olduğunu göstermektedir [12-13].

$n$ idealite faktörü kullanılarak seri direnç etkisinin hesaplanması için Cheung tarafından önerilen diğer bir yöntem $\mathrm{H}$ fonksiyonun kullanılmasıdır ve

$H(I)=V-n \frac{k T}{q} \ln \left(\frac{I}{A A^{*} T^{2}}\right)$

ile 
$H(I)=I R_{s}+n \phi_{\mathrm{b} 0}$

şeklinde tanımlanır. Burada $\phi_{\mathrm{b} 0}$, besleme voltaj1 sıfir olduğunda eklem engel yüksekliğidir [11]. Buradan görüleceği üzere akıma (I) karşı çizilen $H(I)$ grafiğinin eğimi direkt seri direnç değerini, $R_{s}$ verecektir. Örnek bir $H(I)-I$ grafiği $23{ }^{\circ} \mathrm{C}$ için Şekil 4 'te verilmiştir.

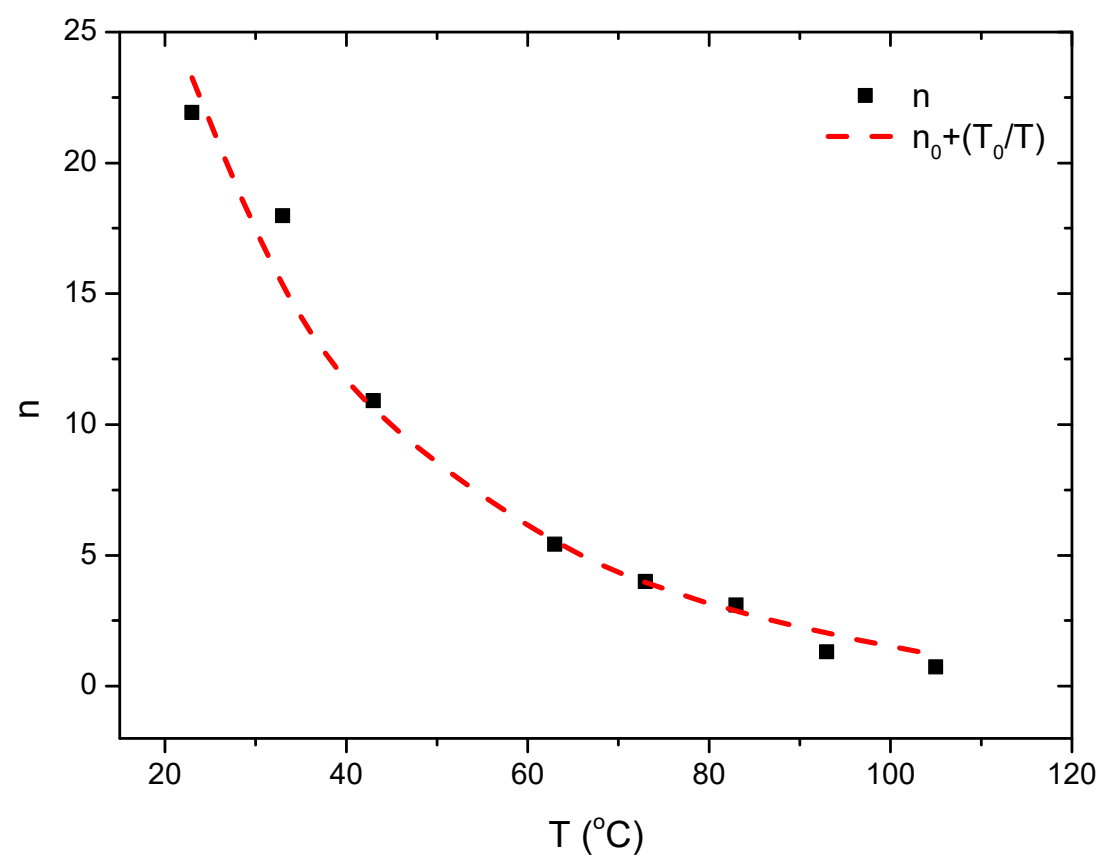

Şekil 3. Diyot idealite faktörü, $n$ 'in sıcaklıkla değişimi

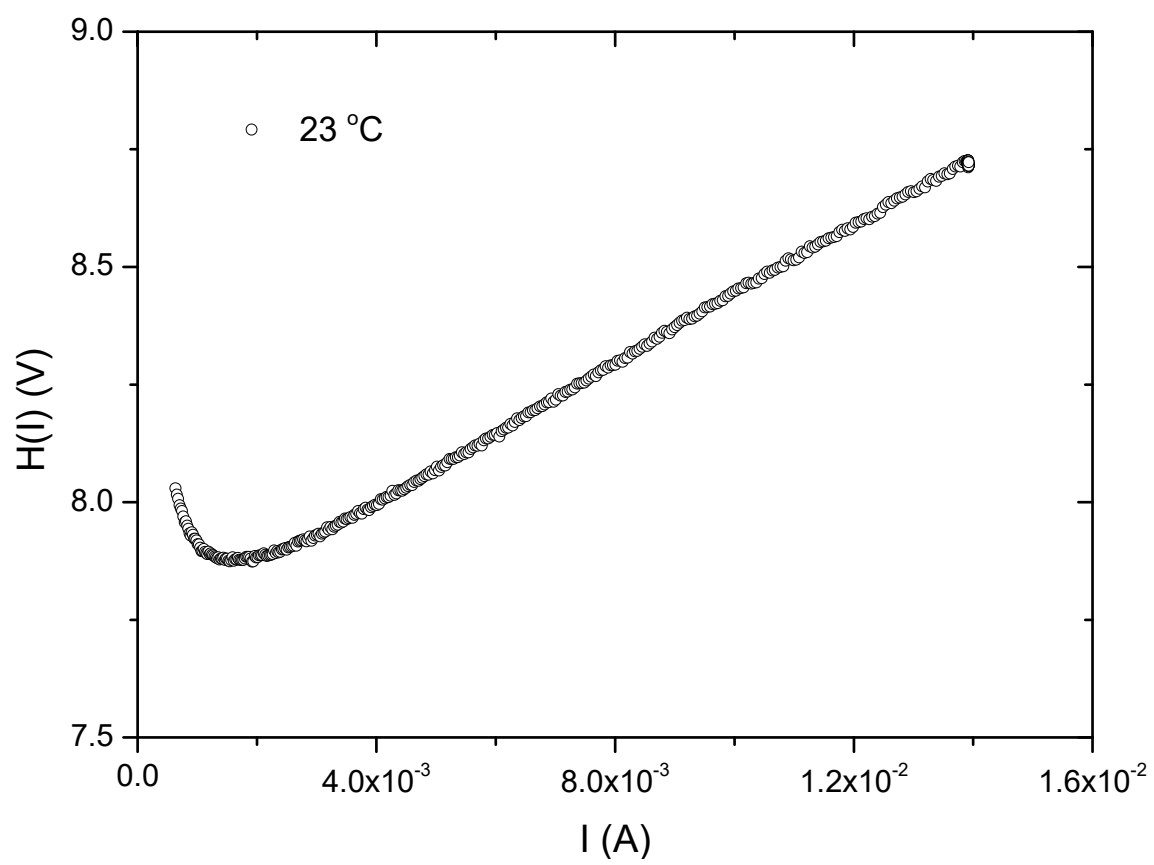

Şekil 4. $23{ }^{\circ} \mathrm{C}$ sicaklıkta $H(I)-I$ değișimi grafiğii. 
$23-103{ }^{\circ} \mathrm{C}$ arsındaki tüm sıcaklıklarda çizilen $H(I)$ - $I$ grafiklerindeki doğrusal bölgeler için seri direnç, $R_{S}$ değerleri hesaplanmış ve Cheung'in ilk modelinden hesaplanan değerlerle birlikte Şekil 5'deki grafikte sıcaklığa bağlı olarak gösterilmiştir.

Grafik incelendiğinde seri direnç, $R_{s}$ değerlerinin $70-110 \Omega$ arasında değerler aldığ ve iki farklı Cheung modelinin neredeyse tüm sıcaklıklarda aynı $R_{s}$ değerlerini verdiği görülmektedir. Metal yarıiletken yapılarla ilgili yapılan önceki pek çok çalışmada bu uyum yöntemin güvenilirliği ve elde edilen değerlerin doğruluğuyla ilişkilendirilmiştir [14]. Dolayısıyla ölçüm yönteminin ve elde edilen değerlerin ele alınan aygıtın seri direnç değerlerini vermede büyük bir doğruluğa sahip olduğu söylenebilir.

Grafikte gözlenen bir diğer durum sicaklığa bağlı olarak artan $R_{s}$ değerlerinin belirli bir sıcaklıktan $\left(60^{\circ} \mathrm{C}\right)$ sonra düşmeye başlamasıdır. Diyot idealite faktörünün, $n$ sıcaklığa bağlı değişiminde (Şekil 2) akım iletim mekanizmasında belirgin bir değişim görülmemektedir. Dolayısıyla $R_{s}$ 'teki bu değişime daha yakından bakılmıştır.

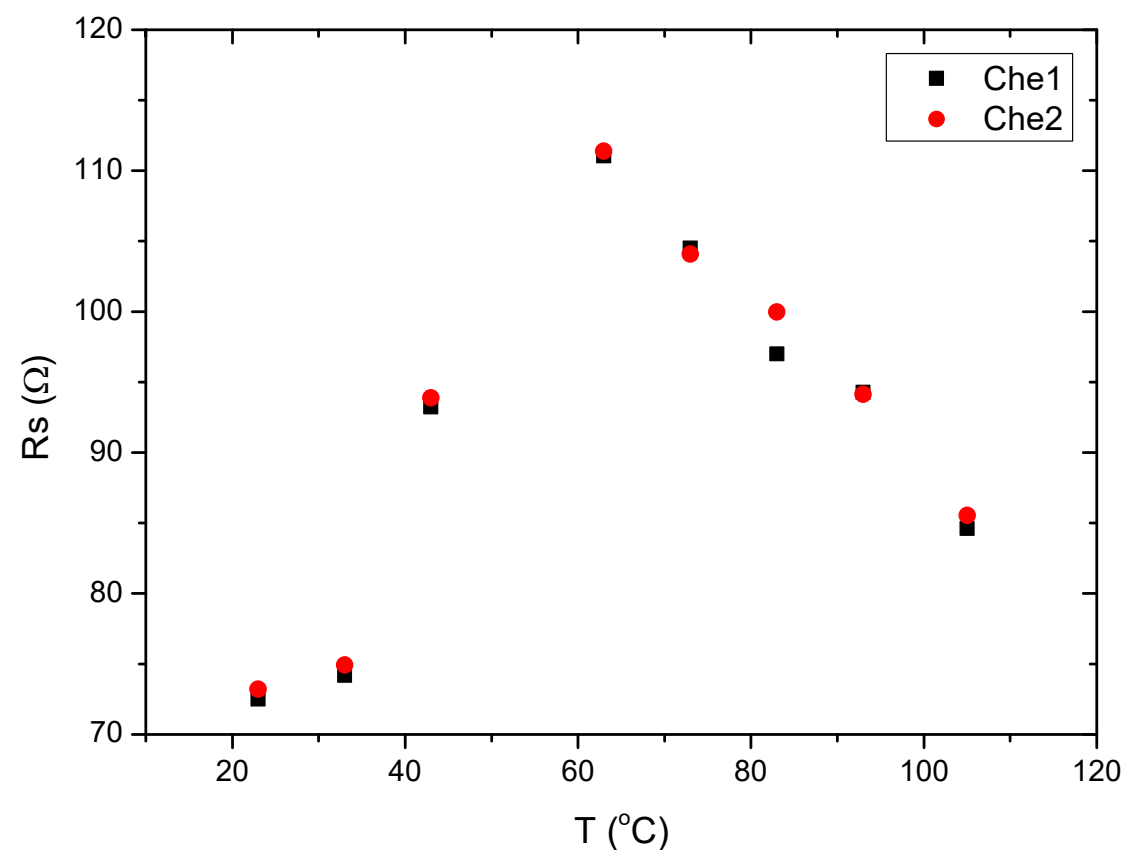

Şekil 5. Seri direnç, $R_{s}^{\prime}$ in iki farklı Cheung yaklaşımına göre sıcaklıkla değişimi

Schottky diyotlarda seri direncin akım - voltaj ve frekans bağımlı kapasitans, kondüktans ölçümlerinden hesaplanması konusunda literatürde pek çok çalışma bulunmaktadır. Sicaklık veya frekansa bağlı seri dirençteki değişimler bu çalışmalarda da elde edilmiştir $[15,16]$. Bülbül ve arkadaşları tarafindan $\mathrm{Al} / \mathrm{Si}_{3} \mathrm{~N}_{4} / \mathrm{p}-\mathrm{Si}$ aygıtlar üzerine yapılan çalışmada [16] hesaplanan sıcaklık bağımlı Rs değerlerinde bir pik gözlenmiş ve bu durum metal - yariiletken ara yüzeyinde tuzak seviyelerindeki yüklerin, sıcaklıkla yeterli enerjiye sahip olunca serbest hale geçmesiyle açıklanmıştır. Yine Korucu ve Duman tarafından $\mathrm{Au} / \mathrm{SiO}_{2} / \mathrm{p}$-Si aygıtlar üzerine yapılan çalışmada Rs değerlerinde sicaklığa bağlı bir pik belirlenmiş ve yazarlar tarafindiyotdan ara yüzeydeki durumların dağılımıyla ilişkilendirilmiştir [17]. Dolayısıyla literatürde çoğu örnekte görülebileceği ve idealite faktörünün sıcaklıkla değiş̧iminde de gözlendiği üzere metal - yariiletken ara yüzeyindeki durumlar ve buradaki yük taşıyıcıları aygıt davranışını önemli ölçüde etkilemektedir. 


\section{Tartışma ve sonuç}

$\mathrm{Bu}$ çalışmada UV ölçümlerinde yaygın olarak kullanılan GUVA S12SD Schottky diyotun karanlıkta sıcaklık bağımlı akım - voltaj ölçümleri yapılmıştır. Ölçüm sistemi olarak uygun maliyetli ve nispeten kolay uygulanabilir bir yöntem önerilmiş ve başarıyla uygulanmıştır. Ölçümler sonucunda aygıtın diyot idealite faktörü belirlenmiş ve akım iletiminin termiyonik alan yayılım mekanizmasıyla açıklanabileceği görülmüştür. Yine iki farklı yöntemle sıcaklık bağımlı seri direnç değerleri hesaplanmış ve bu değerlerde sicaklığa bağımlı bir değişim gözlenmiştir. Tüm sonuçlar ortak değerlendirildiğinde aygıtın metal - yarıiletken ara yüzündeki durumların aygıtın davranış1 üzerinde önemli etkisi olduğu belirlenmiştir. Özellikle artan sıcaklıkla seri dirençteki önce artış ve sonra azalma şeklindeki davranış aygıtın yüksek sıcaklıklarda kullanımında göz önüne alınması gereken bir durum olarak ortaya çıkmaktadır.

\section{Kaynaklar}

[1] Patel, M., Kim, H.S., Park, H.H. ve Kim J., Active adoption of void formation in metal-oxide for all transparent super-performing photodetectors, Scientific Reports, 6(1), 25461, (2016).

[2] Muñoz, E., (Al,In,Ga)N-Based photodetectors. some materials issues, Physica Status Solidi (B), 244(8), 2859-77, (2007).

[3] GUVA-S12SD SMD type UV sensor data sheet, Genicom Co., Korea, (2010).

[4] Brmarcum, Semiconductor curve trace with the analog discovery 2 http://www.instructables.com/id/Semiconductor-Curve-Tracer-With-the-Analog Discove/ (erişim tarihi: 03.09.2018)

[5] Sze, S.M., Physics of Semiconductor Devices, Second Edition, John Wiley \& Sons, New York, (1981).

[6] Rhoderick E.H. ve Williams, R.H., Metal - Semiconductor Contacts, Second Edition, Clarendon Press, Oxford, (1988).

[7] Aydın, M.E., Yakuphanoğlu, F., Eom, J-H. ve Hwang D-H., Electrical characterization of Al/MEH-PPV/p-Si Schottky diode by current-voltage and capacitance-voltage methods, Physica B, 387, 239 - 244, (2007).

[8] Kavasoglu, N., Tozlu, C., Pakma, O., Kavasoglu, A.S., Ozden, S., Metin, B., Birgi, O. ve Oktik, S., Room-temperature interface state analysis of Au/Poly(4vinyl phenol)/p-Si structure, Synthetic Metals, 159 (17-18), 1880-1884, (2009).

[9] Norde, H., A modified forward I -V plot for Schottky diodes with high series resistance, Journal of Applied Physics, 50, 5052, (1979).

[10] Aubry, V. ve Meyer, F., Schottky diodes with high series resistance: Limitations of forward IV methods, Journal of Applied Physics, 76, 7973, (1994).

[11] Cheung S.K. ve Cheung N.W., Extraction of Schottky diode parameters from forward current-voltage characteristics, Applied Physics Letters, 49 (2), 85 87, (1986).

[12] Altındal, Ş., Kanbur, H., Yıldız, D.E. ve Parlak, M., Current conduction mechanism in Al/p-Si Schottky barrier diodes with native insulator layer at low temperatures, Applied Surface Science, 217 (11), 5056 - 5061, (2007).

[13] Aboelfotoh, M.O., Cros A., Svensson B.G. ve Tu, K.N., Schottky-barrier behavior of copper and copper silicide on n-type and p-type silicon, Physical Review B, 41(14), 9819 - 9827, (1990). 
[14] Tataroğlu, A. ve Altındal, Ş., The analysis of the series resistance and interface states of MIS Schottky diodes at high temperatures using I-V characteristics, Journal of Alloys and Compounds, 484, 405 - 409, (2009).

[15] Afandiyeva, İ.M., Dökme, İ., Altındal, Ş., Abdullayeva, L.K. ve Askerov, Sh. G., The frequency and voltage dependent electrical characteristics of Al-TiW$\mathrm{Pd}_{2} \mathrm{Si} / \mathrm{n}-\mathrm{Si}$ structure using $\mathrm{I}-\mathrm{V}, \quad \mathrm{C}-\mathrm{V}$ and $\mathrm{G} / \omega-\mathrm{V}$ measurements, Microelectronic Engineering, 85(2), 365 - 370, (2008).

[16] Bülbül, M.M., Zeyrek, S., Altındal, Ş. and Yüzer, H., On the profile of temperature dependent series resistance in $\mathrm{Al} / \mathrm{Si3N} 4 / \mathrm{p}-\mathrm{Si}$ (MIS) Schottky diodes,Microelectronic Engineering, 83(3), 577 - 581, (2006).

[17] Korucu, D., Duman S., Frequency and temperature dependent interface states and series resistance in $\mathrm{Au} / \mathrm{SiO} 2 / \mathrm{p}$-Si (MIS) diode, Science of Advanced Materials, 7(7), $1291-1297,(2015)$. 